\title{
Genomewide Profiling of Rapamycin Sensitivity in Saccharomyces cerevisiae on Synthetic Medium
}

\author{
Yeon Ji Chang ${ }^{1}$, Chun-Shik Shin ${ }^{1}$, Donghun Han ${ }^{2}$, \\ Jiyun $\mathrm{Kim}^{2}$, Kangin $\mathrm{Kim}^{2}$, Yong-Min Kwon ${ }^{2}$ and \\ Won-Ki Huh ${ }^{1 *}$ \\ ${ }^{1}$ School of Biological Sciences, and Research Center \\ for Functional Cellulomics, Institute of Microbiology, \\ Seoul National University, Seoul 151-747, Korea, ${ }^{2}$ Korea \\ Science Academy, Busan 614-822, Korea
}

\begin{abstract}
The target of rapamycin (TOR) signaling pathway is a conserved pathway that regulates eukaryotic cell growth in response to environmental cues. Chemical genomic approaches that profile rapamycin sensitivity of yeast deletion strains have given insights into the function of TOR signaling pathway. In the present study, we analyzed the rapamycin sensitivity of yeast deletion library strains on synthetic medium. As a result, we identified 130 strains that are hypersensitive or resistant to rapamycin compared with wild-type cells. Among them, 36 genes are newly identified to be related to rapamycin sensitivity. Moreover, we found 16 strains that show alteration in rapamycin sensitivity between complex and synthetic media. We suggest that these genes may be involved in part of TOR signaling activities that is differentially regulated by media composition.
\end{abstract}

Keywords: rapamycin, Saccharomyces cerevisiae, TOR signaling pathway, yeast deletion library

\section{Introduction}

The target of rapamycin (TOR) kinase is structurally and functionally conserved in eukaryotic organisms from yeast to human. In yeast, there are two TOR proteins, Tor1 and Tor2, which function in two distinct TOR complexes, named TOR complex 1 (TORC1) and TOR complex 2 (TORC2). TORC1 contains either Tor1 or Tor2 as one of its subunits, whereas TORC2 contains only Tor2, but not Tor1 (Loewith et al., 2002). TORC1 positively controls cell growth in response to nutrient availability. It stimulates anabolic processes like protein synthesis

*Corresponding author: E-mail wkh@snu.ac.kr

Tel +82-2-880-9243, Fax +82-2-873-4740

Accepted 6 December 2010 and inhibits catabolic processes like autophagy (Kamada et al., 2004; Mayer and Grummt, 2006; Rohde et al., 2001). Rapamycin, a macrolide antibiotic, is a specific inhibitor of TORC1. Internalized rapamycin binds to Fpr1, and rapamycin-Fpr1 complex can bind to TOR protein only in TORC1 (Heitman et al., 1991; Koltin et al., 1991; Loewith et al., 2002). Because rapamycin treatment can easily induce some physiological characteristics that come from TORC1 inhibition, rapamycin treatment is broadly used to identify function of TORC1. The function of mammalian TORC1 is similar to yeast TORC1 and inhibition pathway by rapamycin-FKBP is also well conserved (Hara et al., 2002; Kim et al., 2002).

Yeast deletion library created by the Saccharomyces Genome Deletion Project (Giaever et al., 2002; Winzeler et al., 1999) is composed of 4,847 MATa deletion strains that were generated by replacing each open reading frame with a kanamycin resistance marker, KanMX4. Gene disruption is a fundamental approach to understand the function of a gene. By observing changes in phenotypes or responses to specific stimulus, we can infer the function of the gene. Yeast deletion library enabled systematic analyses to investigate various cellular responses such as tolerance of extracellular stimulus, sensitivity to drug, and longevity (Abe and Minegishi, 2008; Chan et al., 2000; Kaeberlein et al., 2005; Xie et al., 2005).

Investigation into the rapamycin sensitivity of mutants has given insights into the mechanism of TOR signaling pathway. The first discovery of TOR protein in yeast came from isolation of rapamycin-resistant mutants, and various TOR signaling effectors were identified from rapamycin sensitivity studies (Heitman et al., 1991). Previously, two groups performed high-throughput rapamycin sensitivity screening using yeast deletion library and identified total 464 genes whose deletions confer the alteration of sensitivity to rapamycin (Chan et al., 2000; Xie et al., 2005).

Yeast extract-peptone-dextrose (YPD) and synthetic complete (SC) media are commonly used for yeast cultivation, but their compositions are quite different. Recently, it was reported that chronological lifespan in yeast is differentially regulated between YPD and SC media (Lastauskiene and Citavicius, 2008; Weinberger et al., 2010). Taking into account the fact that the activity of TOR signaling pathway is dependent on nutrient availability, it is reasonable to assume that media composition would affect rapamycin sensitivity of cells. While 
both of previous high-throughput rapamycin sensitivity screenings were performed on YPD medium, in the present study, we performed rapamycin sensitivity screening of yeast deletion library on SC medium to find novel effectors of TOR signaling pathway. We found 130 mutants that are hypersensitive or resistant to rapamycin on SC media, and 16 mutants that show different sensitivity between YPD and SC media. We suggest that these genes may be involved in TOR signaling pathway that is differentially regulated by media composition.

\section{Methods}

\section{Yeast strains, medium and reagents}

4,847 MATa strains in yeast deletion library created by the Saccharomyces Genome Deletion Project (http:// www-sequence.stanford.edu/group/yeast_deletion_project/deletions3.html) were used to profile growth rates in response to rapamycin. SC medium $(0.67 \%$ yeast nitrogen base without amino acids, $2 \%$ glucose, and appropriate amino acids) and YPD medium (1\% yeast extract, $2 \%$ peptone, and $2 \%$ glucose) were prepared as previously described (Sherman, 2002). Cells were grown in $30^{\circ} \mathrm{C}$. Rapamycin (Tecoland) was dissolved in DMSO and used at indicated concentrations $(10 \mathrm{ng} / \mathrm{ml}, 100$ $\mathrm{ng} / \mathrm{ml}$, and $200 \mathrm{ng} / \mathrm{ml}$ ).

\section{Rapamycin sensitivity screening}

Yeast deletion library strains were incubated in YPD for 1 day in 96-deep-well plates and spotted onto SC agar medium containing $10 \mathrm{ng} / \mathrm{ml}$ or $100 \mathrm{ng} / \mathrm{ml}$ rapamycin by using a 96-pin tool (V\&P Scientific; VP408B). After incubation for $4 \sim 6$ days, rapamycin-resistant or -hypersensitive strains were selected by comparing with other colonies in the same plate. Between each spotting, $96-$ pin tool was cleaned by $10 \%$ bleach, distilled water, and flaming with ethanol.

\section{Data analysis using the Gene Ontology (GO) Slim Mapper and the Search Tool for the Retrieval of Interacting Genes/Proteins (STRING)}

Selected genes were categorized by biological processes using the GO Slim Mapper available at the Saccharomyces Genome Database (SGD; www.yeastgenome.org). Genes mapped to "other function" or "not yet annotated" were eliminated from total 4,847 genes, and the remaining 2,757 gene were compared with our candidate genes. The STRING is a web-based resource for the retrieval of gene/protein interactions and is avail-
A
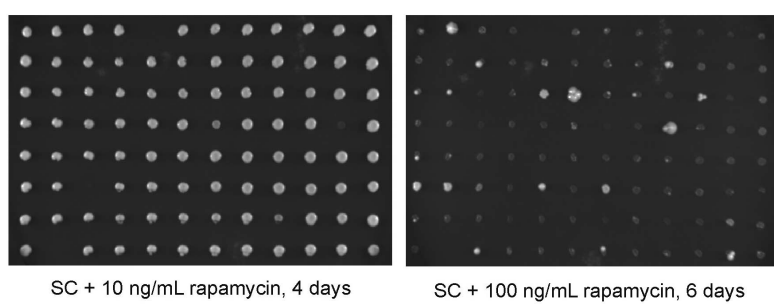

$\mathrm{SC}+100 \mathrm{ng} / \mathrm{mL}$ rapamycin, 6 days

\section{B}
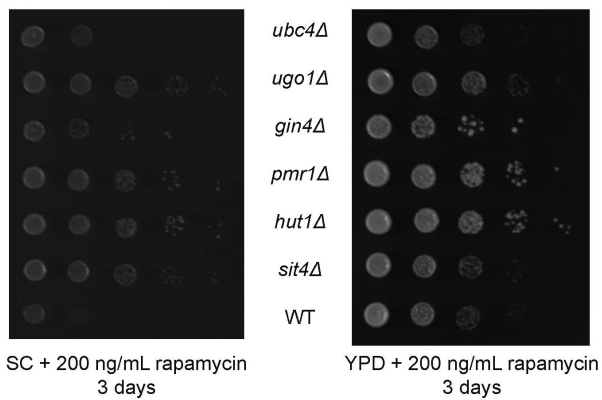

C

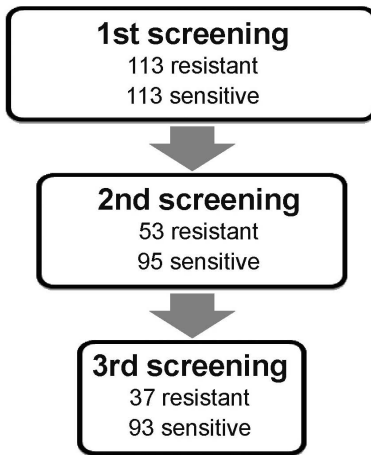

Fig. 1. Profiling of rapamycin sensitivity on SC medium. (A) Rapamycin sensitivity of each gene deletion strain was tested using a 96-pin tool. Yeast deletion library strains grown in YPD for 1day were spotted on SC agar medium containing $10 \mathrm{ng} / \mathrm{mL}$ or $100 \mathrm{ng} / \mathrm{mL}$ rapamycin. Rapamycin-resistant or -hypersensitive strains were selected after incubation at $30^{\circ} \mathrm{C}$ for $4 \sim 6$ days. (B) Spotting assay was performed with 53 rapamycin-resistant mutants and 95 rapamycin-hypersensitive mutants. Exponentially growing cells $\left(\mathrm{OD}_{600}=1.0\right)$ in YPD medium were 10-fold serially diluted and spotted onto SC and YPD agar plates containing $200 \mathrm{ng} / \mathrm{mL}$ rapamycin. (C) Summary of rapamycin sensitivity screening on SC medium. At first and second screenings performed using a 96-pin tool, we identified 53 rapamycin-resistant mutants and 95 rapamycin-sensitive mutants. They were confirmed by spotting assay and 18 genes were eliminated from the candidates list.

able at http://string.embl.de/. Predicted interactions between genes are denoted as lines with confidence value 
for each prediction (Jensen et al., 2009; von Mering et al., 2003).

\section{Results}

\section{Genomewide screening of rapamycin sensitivity on SC medium}

We measured the rapamycin sensitivity of yeast deletion library strains on SC medium by spotting using a 96-pin tool ( 1 to $2 \mu \mathrm{l}$ of inoculum per pin). Yeast deletion library strains were inoculated into YPD liquid medium in 96-deep-well plates and incubated for 1 day. These fully grown cells were spotted using a 96-pin tool onto SC agar medium containing $10 \mathrm{ng} / \mathrm{ml}$ or $100 \mathrm{ng} / \mathrm{ml}$ rapamycin. We selected rapamycin-hypersensitive strains from SC medium containing $10 \mathrm{ng} / \mathrm{ml}$ rapamycin, and rapamycin-resistant strains from SC medium containing $100 \mathrm{ng} / \mathrm{ml}$ rapamycin. Although we could not exactly adjust the volume of each inoculum, most of colonies except those of rapamycin-sensitive strains showed similar size on medium containing $10 \mathrm{ng} / \mathrm{ml}$ rapamycin (Fig. 1A). This observation indicates that the slight difference in the amount of inoculated cells between spots is ignorable in this screening.

From the first screening, 113 rapamycin-resistant strains and 113 rapamycin-hypersensitive strains were isolated. To compare the rapamycin sensitivity of mutant cells with wild-type cells as a control and to remove the variation between plates, we collected rapamycin-resistant or -hypersensitive strains, and performed a second screening using a 96-pin tool. From the second screening, we selected 53 rapamycin-resistant strains and 95 rapamycin-hypersensitive strains.

Next, we confirmed the rapamycin sensitivity of these deletion mutants by spotting assay. Exponentially growing cells $\left(O D_{600}=1.0\right)$ in YPD medium were 10 -fold serially diluted and spotted onto SC and YPD agar plates containing $200 \mathrm{ng} / \mathrm{mL}$ rapamycin (Fig. 1B). We scored the rapamycin sensitivity of cells from +++++ to ----. Strains that got the score of 0 or + were ruled out because their rapamycin sensitivity was not significantly different from that of wild-type cells. As done previously, we named the genes whose deletions confer rapamycin resistance or hypersensitivity as $\mathrm{RR}$ or $\mathrm{RH}$ genes, respectively (Chan et al., 2000). Finally, we obtained 37 $\mathrm{RR}$ genes and $93 \mathrm{RH}$ genes (Fig. 1C), which are listed in Table 1.

\section{Functional analysis of RR and RH genes}

In previous high-throughput studies, Xie et al. (2005) identified 396 genes that are related to rapamycin sensitivity, and Chan et al. (2000) identified 27 RR genes and $89 \mathrm{RH}$ genes. Comparison of these results with our data revealed that 80 genes $(62 \%)$ in our list overlap with those from previous results (Fig. 2A). Among the remaining 50 genes in our data, 14 genes have been shown to be related to rapamycin sensitivity by other previous studies (Dudley et al., 2005; Fournier et al., 2010; Huber et al., 2009; Leidel et al., 2009; Parsons et al., 2004; Snowdon et al., 2008; Wu et al., 2000). 10 RR genes and $26 \mathrm{RH}$ genes that were newly identified by our genomewide analysis on SC medium are underlined in Table 1.

Using the GO Slim Mapper tool available at the SGD, we analyzed the enrichment of biological processes for $109 \mathrm{RR}$ and $\mathrm{RH}$ genes whose functions are known. Notably, we found that translation-related genes occupy $20 \%$ of RR genes (Fig. 2B). This observation correlates

Table 1. $37 \mathrm{RR}$ genes and $93 \mathrm{RH}$ genes identified in this study

\begin{tabular}{|c|c|}
\hline Sensitivity score & Genes $^{a}$ \\
\hline++++ & $\begin{array}{l}\text { BTS1, GLN3, HUR1, IRC21, MAP1, MEC3, MRP7, MRPL10, MRPL36, MRPL6, MRPS5, MSH1, PBI2, PMR1, RRD1, RRD2, } \\
\text { RTG1, SIT4, TIP41, TUF1, TVP18, UGO1, YDR114C, YOR199W, YNLO4OW, YNR047W, YOR200W }\end{array}$ \\
\hline++++ & ATP5, INH1 \\
\hline $\begin{array}{l}+++ \\
++\end{array}$ & $\begin{array}{l}\text { FUM1, NCL1, PPM1, SPT7, UME1, YPL105C } \\
\text { SAP190, } \frac{\text { VAC7 }}{P 1011}\end{array}$ \\
\hline- & NDE1, RPL21A \\
\hline-- & $\begin{array}{l}\text { ADE3, AIM22, APL2, ARP8, ATG11, BFR1, BUD30, CAX4, DIA2, ETR1, IWR1, KES1, KTI12, LCB4, LST4, MUP1, NCS6, } \\
\text { PAC10, PAR32, PIH1, PKR1, REF2, RPL13B, RTT103, SAC3, SAT4, SER1, SHE4, SNX4, STO1, SWI6, THP2, UBA4, UBP3, } \\
\text { VAN1, VID28, YBL100C, YDL172C, YJL120W, YLR358C }\end{array}$ \\
\hline--- & $\begin{array}{l}\text { APQ12, BCK1, CEM1, DPH2, ELP2, ELP3, FYV4, GTR1, HIT1, HOM2, HOM6, HTD2, ILV1, KRE6, LSM1, LST7, MEH1, } \\
\text { MMS22, NAS2, NIR1, NUP84, PIB2, PIN4, PRO2, RAV1, REG1, RNR4, RPE1, RPL12B, RPL34B, RPS8A, SCP160, SER2, } \\
\text { TCO89, THP1, URE2, URM1, VPS54, YIA6, YKE2, YDL118W, YILO77C, YILO92W, YJRO18W } \\
\text { CCR4, CHS5, ERG3, HOM3, PRS3, SLT2, THR1 }\end{array}$ \\
\hline
\end{tabular}

${ }^{a} 10$ RR genes and $26 \mathrm{RH}$ genes newly identified by our genomewide analysis on SC medium are underlined. 
A

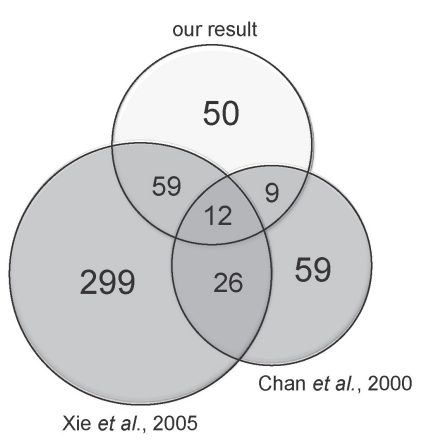

B

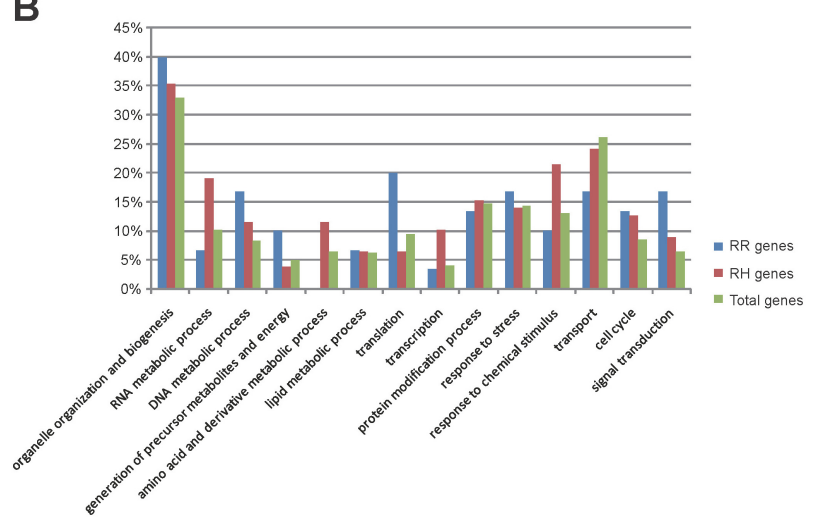

C

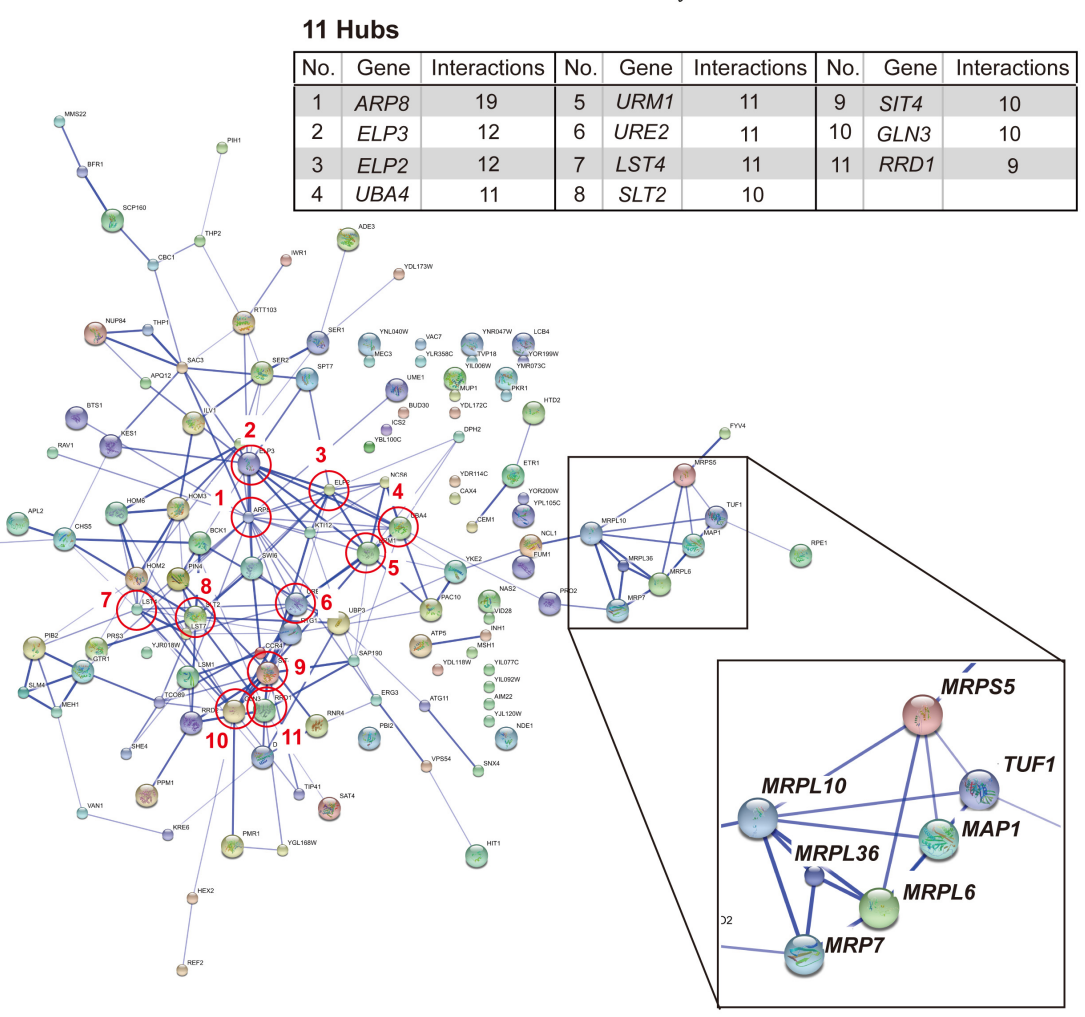

Fig. 2. Analysis of RR and $\mathrm{RH}$ genes found in this study. (A) Among $130 \mathrm{RR}$ and $\mathrm{RH}$ genes that we found, 80 genes overlapped with those from two previous high-throughput screening results. (B) The enrichment of biological processes for RR and RH genes was analyzed using the GO Slim Mapper tool available at the SGD. 2,757 genes for total genes, 30 genes for RR genes, and 79 genes for RH genes were analyzed. (C) An interaction map between 130 RR and RH genes drawn by the STRING. Each node is a gene, and a line between two nodes means a predicted interaction. The thickness of a line represents confidence value for prediction. 11 most interacting hub genes are shown in red circle and listed in a table. A cluster composed of MRP genes is zoomed in.

with the well-known fact that TORC1 controls cell growth by regulating translation. It is also notable that RNA metabolic process-related genes are about twice enriched in $\mathrm{RH}$ genes. This result suggests that RNA metabolism may be closely related to TOR signaling pathway. However, the relationship between RNA metabolism and TOR signaling pathway is not clearly de- fined yet

In addition, we generated an interaction map of 130 $\mathrm{RR}$ or RH genes using the STRING and found 11 interaction hubs that have more than 9 interactions (Fig. 2C). Notably, these hubs included the URE2, SIT4, GLN3, and $R R D 1$ genes that are known to play important roles in TOR signaling pathway (Beck and Hall, 1999; 


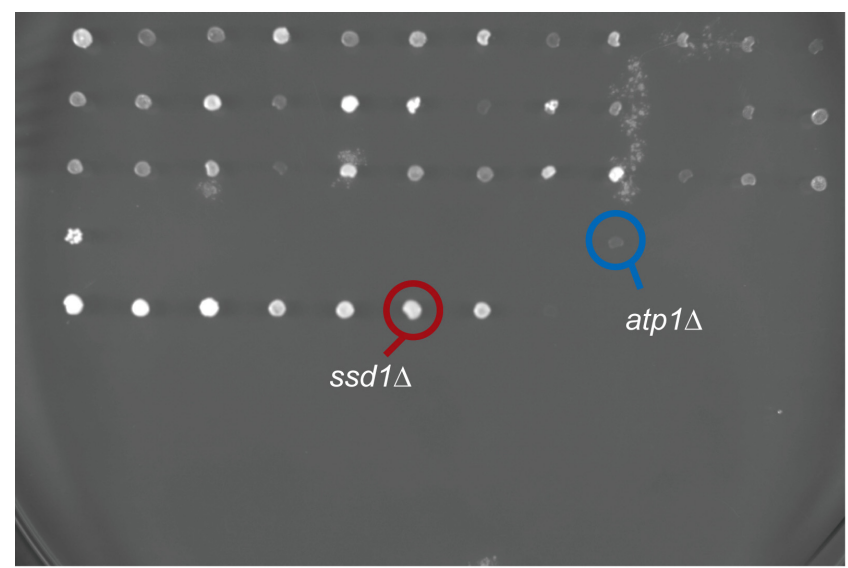

$\mathrm{SC}+100 \mathrm{ng} / \mathrm{mL}$ rapamycin, 3 days

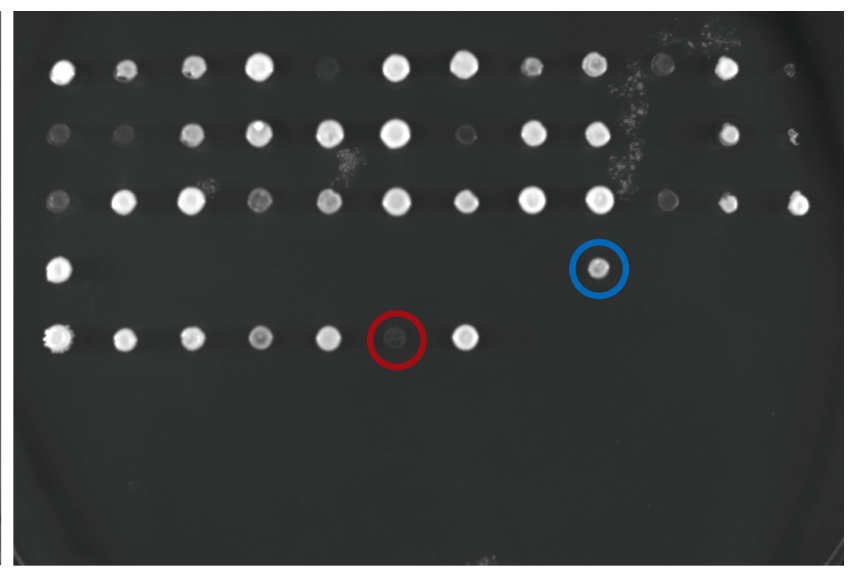

YPD + $100 \mathrm{ng} / \mathrm{mL}$ rapamycin, 3 days

Fig. 3. Altered rapamycin sensitivity between YPD and SC media. 45 strains that showed significant resistance or hypersensitivity to rapamycin in other previous studies but were not included in the rapamycin-responsive candidates identified from our screening were spotted onto SC (left panel) and YPD medium containing $100 \mathrm{ng} / \mathrm{mL}$ rapamycin (right panel).

Carvalho and Zheng, 2003; Rohde et al., 2004). This observation raises a possibility that other hub genes may also be closely related to TOR signaling pathway. Among the hub genes, ARP8, a component of chromatin-remodeling complexes, showed interactions with the most genes within 130 genes. The relationship between ARP8 and TOR signaling pathway is not identified yet. Yeast has about 60 mitochondrial ribosomal proteins (MRPs). We also noticed a cluster in the interaction map which is mainly composed of five MRP genes-MRP7, MRPL10, MRPL36, MRPL6, and MRPS5. Alteration in the rapamycin sensitivity of these MRP gene mutants has not been reported before, except for MRP7. This result suggests that proteins involved in mitochondrial function are highly likely to be related to SC-specific alteration in the rapamycin sensitivity of cells.

\section{Identification of strains showing difference in rapamycin sensitivity between YPD and SC me- dia}

Next, we tested whether rapamycin sensitivity could be influenced by media composition. We spotted 130 $\mathrm{RH}$ and RR strains not only on SC medium but also on YPD medium, and compared the growth of strains between two media. We found that 25 strains did not respond to rapamycin in YPD, and among them 14 genes (RTG1, YPL105C, SIT4, ARP8, DPH2, RTT103, YIA6, AIM22, FYV4, HTD2, HIT1, NUP84, YBL100C, and ETR1) were included in $\mathrm{RR}$ and $\mathrm{RH}$ genes newly identified from our assay. Sit4 is a well-known effector of TOR signaling pathway. When TORC1 is inhibited by rapamycin, dephosphorylated Tap42 is released from
Rrd1/Sit4 complex, and then activated Sit4 functions in regulatory roles in the inactive TOR pathway (Di Como and Arndt, 1996; Rohde et al., 2004). Deletion of RRD1 encoding a coactivator of Sit4 phosphatase confers significant increase in rapamycin resistance. However, it has not been reported yet whether sit4 $\Delta$ mutant shows altered fitness response to rapamycin. Our finding that sit4 $\Delta$ mutant is resistant to rapamycin on SC medium is consistent with the known function of Sit4 in TOR signaling pathway, and demonstrates the effectiveness of rapamycin sensitivity screening using SC medium.

Since media composition can affect the rapamycin sensitivity of cells as shown above, it is also conceivable that strains that show altered rapamycin sensitivity in YPD medium but not in SC medium may exist. From previous results by other studies, we chose 45 strains that showed significant resistance or hypersensitivity to rapamycin but were not included in the rapamycin-responsive candidates identified from our screening. Interestingly, two strains showed opposite sensitivity to rapamycin between YPD and SC media (Fig. 3). ssd1 $\Delta$ mutant was hypersensitive to rapamycin on YPD medium, but showed resistance to rapamycin on SC medium. On the contrary, atp1 1 mutant was resistant to rapamycin on YPD medium, but hypersensitive to rapamycin on SC medium. Ssd1 is a protein that functions in the maintenance of cellular integrity, and Atp1 is a subunit of mitochondrial ATP synthase (Kaeberlein and Guarente, 2002; Takeda et al., 1986). Together, we found 16 strains $(r \operatorname{rg} 1 \Delta, y p / 105 c \Delta$, sit4 $\Delta$, arp8 $\Delta$, dph2 $\Delta$, rtt103 4 , yia6 $\Delta$, aim22 $\Delta$, fyv4 $\Delta$, htd2 $\Delta$, hit1 $\Delta$, nup84 $\Delta, y b / 100 c \Delta$, etr1 $\Delta$, ssd1 $\Delta$, and atp1 $\Delta$ ) that exhibited different rapamycin sensitivity between 
YPD and SC media. This result suggests that some pathways in downstream or upstream of TORC1 are differentially regulated by YPD and SC media.

Although there was no common function of 16 proteins whose deficiency causes different rapamycin sensitivity between YPD and SC media, 7 proteins (Fum1, Yia6, Aim22, Fyv4, Htd2, Etr1, and Atp1) are localized to the mitochondria, and one of the remaining proteins (Rtg1) plays a role in retrograde signaling that transmits changes in mitochondrial function to nuclear gene expression (Huh et al., 2003; Liu and Butow, 2006). High enrichment of mitochondria-related genes in genes whose deficiency causes different rapamycin sensitivity between YPD and SC media suggests that mitochondrial function may be involved in part of TOR signaling activities that is differentially regulated by media composition.

\section{Discussion}

Altered fitness response to rapamycin of a gene deletion strain implies that the deleted gene is possibly related to TOR signaling pathway. Sometimes it gives a clue to how the gene functions in TORC1 signaling. In the present study, we performed a genomewide rapamycin sensitivity analysis on 4,847 strains in yeast deletion library. Through this screening, we identified 130 strains exhibiting altered rapamycin sensitivity phenotype. During the screening work, we could confirm the usefulness of a 96-pin tool in fitness response analysis. A high-density cell arrayer that can print 9,600 strains at once was used for rapamycin sensitivity screening in other studies. However, by using a 96-pin tool, we could retain the original array of yeast deletion library that is stored in a 96-well format, and identify the size of each colony. Several well-known TORC1 singling effectors, such as Gln3, Ure2, Npr1, and Tip41, were used to support the reliability of rapamycin sensitivity screening result in the previous study (Xie et al., 2005). We could also find these genes in our first screening, which supports the reliability of our screening result.

Importantly, we found that rapamycin sensitivity can be altered by media composition in some gene deletion strains. Among $130 \mathrm{RH}$ and RR strains identified in our study, 25 mutant strains exhibited altered rapamycin sensitivity only in SC medium. We also found two mutant strains that show opposite rapamycin sensitivity between YPD and SC media. Genes deleted in these strains are supposed to be related to part of TORC1 activity that is differentially regulated by media composition. Further investigation into the relationship between these genes and TORC1 activity will provide deeper understanding of the operational mechanism of TOR sig- naling pathway.

\section{Acknowledgements}

This work was supported by the 21C Frontier Microbial Genomics and Application Center Program (MG-112008-09-004-00) and the Basic Research Promotion Fund of the Korea Research Foundation (KRF-2007-314E00036), Republic of Korea. Y.J.C. and C.-S.S. were supported by the BK21 Research Fellowship from the Ministry of Education, Science and Technology, Republic of Korea.

\section{References}

Abe, F., and Minegishi, H. (2008). Global screening of genes essential for growth in high-pressure and cold environments: searching for basic adaptive strategies using a yeast deletion library. Genetics 178, 851-872.

Beck, T., and Hall, M.N. (1999). The TOR signalling pathway controls nuclear localization of nutrient-regulated transcription factors. Nature 402, 689-692.

Carvalho, J., and Zheng, X.F. (2003). Domains of GIn3p interacting with karyopherins, Ure2p, and the target of rapamycin protein. J. Biol. Chem. 278, 16878-16886.

Chan, T.F., Carvalho, J., Riles, L., and Zheng, X.F. (2000). A chemical genomics approach toward understanding the global functions of the target of rapamycin protein (TOR). Proc. Natl. Acad. Sci. USA 97, 13227-13232.

Di Como, C.J., and Arndt, K.T. (1996). Nutrients, via the Tor proteins, stimulate the association of Tap42 with type $2 \mathrm{~A}$ phosphatases. Genes Dev. 10, 1904-1916.

Dudley, A.M., Janse, D.M., Tanay, A., Shamir, R., and Church, G.M. (2005). A global view of pleiotropy and phenotypically derived gene function in yeast. Mol. Syst. Biol. 1, 2005.0001.

Fournier, M.L., Paulson, A., Pavelka, N., Mosley, A.L., Gaudenz, K., Bradford, W.D., Glynn, E., Li, H., Sardiu, M.E., Fleharty, B., Seidel, C., Florens, L., and Washburn, M.P. (2010). Delayed correlation of mRNA and protein expression in rapamycin-treated cells and a role for Ggc1 in cellular sensitivity to rapamycin. Mol. Cell Proteomics 9, 271-284.

Giaever, G., Chu, A.M., Ni, L., Connelly, C., Riles, L., Veronneau, S., Dow, S., Lucau-Danila, A., Anderson, K., Andre, B., Arkin, A.P., Astromoff, A., El-Bakkoury, M., Bangham, R., Benito, R., Brachat, S., Campanaro, S., Curtiss, M., Davis, K., Deutschbauer, A., Entian, K.D., Flaherty, P., Foury, F., Garfinkel, D.J., Gerstein, M., Gotte, D., Guldener, U., Hegemann, J.H., Hempel, S., Herman, Z., Jaramillo, D.F., Kelly, D.E., Kelly, S.L., Kotter, P., LaBonte, D., Lamb, D.C., Lan, N., Liang, H., Liao, H., Liu, L., Luo, C., Lussier, M., Mao, R., Menard, P., Ooi, S.L., Revuelta, J.L., Roberts, C.J., Rose, M., Ross-Macdonald, P., Scherens, B., Schimmack, G., Shafer, B., Shoemaker, D.D., Sookhai-Mahadeo, S., Storms, R.K., Strathern, J.N., Valle, G., Voet, M., 
Volckaert, G., Wang, C.Y., Ward, T.R., Wilhelmy, J., Winzeler, E.A., Yang, Y., Yen, G., Youngman, E., Yu, K., Bussey, H., Boeke, J.D., Snyder, M., Philippsen, P., Davis, R.W., and Johnston, M. (2002). Functional profiling of the Saccharomyces cerevisiae genome. Nature 418, 387-391.

Hara, K., Maruki, Y., Long, X., Yoshino, K., Oshiro, N., Hidayat, S., Tokunaga, C., Avruch, J., and Yonezawa, K. (2002). Raptor, a binding partner of target of rapamycin (TOR), mediates TOR action. Cell 110, 177-189.

Heitman, J., Movva, N.R., Hiestand, P.C., and Hall, M.N. (1991). FK 506-binding protein proline rotamase is a target for the immunosuppressive agent FK 506 in Saccharomyces cerevisiae. Proc. Natl. Acad. Sci. USA 88, 1948-1952.

Huber, A., Bodenmiller, B., Uotila, A., Stahl, M., Wanka, S., Gerrits, B., Aebersold, R., and Loewith, R. (2009). Characterization of the rapamycin-sensitive phosphoproteome reveals that Sch9 is a central coordinator of protein synthesis. Genes Dev. 23, 1929-1943.

Huh, W.K., Falvo, J.V., Gerke, L.C., Carroll, A.S., Howson, R.W., Weissman, J.S., and O'Shea, E.K. (2003). Global analysis of protein localization in budding yeast. Nature 425, 686-691.

Jensen, L.J., Kuhn, M., Stark, M., Chaffron, S., Creevey, C., Muller, J., Doerks, T., Julien, $P_{\text {., Roth, }}$., Simonovic, M., Bork, P., and von Mering, C. (2009). STRING 8--a global view on proteins and their functional interactions in 630 organisms. Nucl. Acids Res. 37, D412-416.

Kaeberlein, M., and Guarente, L. (2002). Saccharomyces cerevisiae MPT5 and SSD1 function in parallel pathways to promote cell wall integrity. Genetics 160, 83-95.

Kaeberlein, M., Powers, R.W., 3rd, Steffen, K.K., Westman, E.A., Hu, D., Dang, N., Kerr, E.O., Kirkland, K.T., Fields, S., and Kennedy, B.K. (2005). Regulation of yeast replicative life span by TOR and Sch9 in response to nutrients. Science 310, 1193-1196.

Kamada, Y., Sekito, T., and Ohsumi, Y. (2004). Autophagy in yeast: a TOR-mediated response to nutrient starvation. Curr. Top Microbiol. Immunol. 279, 73-84.

Kim, D.H., Sarbassov, D.D., Ali, S.M., King, J.E., Latek,

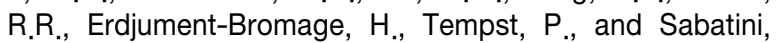
D.M. (2002). mTOR interacts with raptor to form a nutrient-sensitive complex that signals to the cell growth machinery. Cell 110, 163-175.

Koltin, Y., Faucette, L., Bergsma, D.J., Levy, M.A., Cafferkey, R., Koser, P.L., Johnson, R.K., and Livi, G.P. (1991). Rapamycin sensitivity in Saccharomyces cerevisiae is mediated by a peptidyl-prolyl cis-trans isomerase related to human FK506-binding protein. Mol. Cell Biol. 11, 1718-1723.

Lastauskiene, E., and Citavicius, D. (2008). Influence of RAS genes on yeast Saccharomyces cerevisiae cell viability in acid environment. Biologija 54, 150-155.

Leidel, S., Pedrioli, P.G., Bucher, T., Brost, R., Costanzo, M., Schmidt, A., Aebersold, R., Boone, C., Hofmann, K., and Peter, M. (2009). Ubiquitin-related modifier Urm1 acts as a sulphur carrier in thiolation of eukaryotic transfer RNA. Nature 458, 228-232.
Liu, Z., and Butow, R.A. (2006). Mitochondrial retrograde signaling. Annu, Rev. Genet. 40, 159-185.

Loewith, R., Jacinto, E., Wullschleger, S., Lorberg, A., Crespo, J.L., Bonenfant, D., Oppliger, W., Jenoe, P., and Hall, M.N. (2002). Two TOR complexes, only one of which is rapamycin sensitive, have distinct roles in cell growth control. Mol. Cell 10, 457-468.

Mayer, C., and Grummt, I. (2006). Ribosome biogenesis and cell growth: mTOR coordinates transcription by all three classes of nuclear RNA polymerases. Oncogene 25, 6384-6391.

Parsons, A.B., Brost, R.L., Ding, H., Li, Z., Zhang, C. Sheikh, B., Brown, G.W., Kane, P.M., Hughes, T.R., and Boone, C. (2004). Integration of chemical-genetic and genetic interaction data links bioactive compounds to cellular target pathways. Nat. Biotechnol. 22, 62-69.

Rohde, J., Heitman, J., and Cardenas, M.E. (2001). The TOR kinases link nutrient sensing to cell growth. J. Biol. Chem. 276, 9583-9586.

Rohde, J.R., Campbell, S., Zurita-Martinez, S.A., Cutler, N.S., Ashe, M., and Cardenas, M.E. (2004). TOR controls transcriptional and translational programs via Sap-Sit4 protein phosphatase signaling effectors. Mol. Cell Biol. 24, 8332-8341.

Sherman, F. (2002). Getting started with yeast. Methods Enzymol 350, 3-41.

Snowdon, C., Hlynialuk, C., and van der Merwe, G. (2008). Components of the Vid30c are needed for the rapamycin-induced degradation of the high-affinity hexose transporter Hxt7p in Saccharomyces cerevisiae. FEMS Yeast Res. 8, 204-216.

Takeda, M., Chen, W.J., Saltzgaber, J., and Douglas, M.G. (1986). Nuclear genes encoding the yeast mitochondrial ATPase complex. Analysis of ATP1 coding the F1-ATPase alpha-subunit and its assembly. J. Biol. Chem. 261, 15126-15133.

von Mering, C., Huynen, M., Jaeggi, D., Schmidt, S., Bork, P., and Snel, B. (2003). STRING: a database of predicted functional associations between proteins. Nucl. Acids Res. 31, 258-261.

Weinberger, M., Mesquita, A., Caroll, T., Marks, L., Yang, H., Zhang, Z., Ludovico, P., and Burhans, W.C. (2010). Growth signaling promotes chronological aging in budding yeast by inducing superoxide anions that inhibit quiescence. Aging (Albany NY) 2, 709-726.

Winzeler, E.A., Shoemaker, D.D., Astromoff, A., Liang, $H_{\text {., }}$ Anderson, K., Andre, B., Bangham, R., Benito, R., Boeke, J.D., Bussey, H., Chu, A.M., Connelly, C., Davis, K., Dietrich, F., Dow, S.W., El Bakkoury, M., Foury, F., Friend, S.H., Gentalen, E., Giaever, G., Hegemann, J.H.,

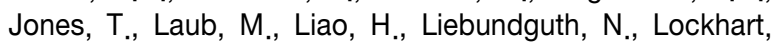
D.J., Lucau-Danila, A., Lussier, M., M'Rabet, N., Menard, P., Mittmann, M., Pai, C., Rebischung, C., Revuelta, J.L., Riles, L., Roberts, C.J., Ross-MacDonald, P., Scherens, B., Snyder, M., Sookhai-Mahadeo, S., Storms, R.K., Veronneau, S., Voet, M., Volckaert, G., Ward, T.R., Wysocki, R., Yen, G.S., Yu, K., Zimmermann, K., Philippsen, P., Johnston, M., and Davis, R.W. (1999). Functional characterization of the $S$. cerevisiae genome 
184 Genomics \& Informatics Vol. 8(4) 177-184, December 2010

by gene deletion and parallel analysis. Science 285, 901-906

Wu, J., Tolstykh, T., Lee, J., Boyd, K., Stock, J.B., and Broach, J.R. (2000). Carboxyl methylation of the phosphoprotein phosphatase $2 \mathrm{~A}$ catalytic subunit promotes its functional association with regulatory subunits in vivo.
EMBO J. 19, 5672-5681.

Xie, M.W., Jin, F., Hwang, H., Hwang, S., Anand, V., Duncan, M.C., and Huang, J. (2005). Insights into TOR function and rapamycin response: chemical genomic profiling by using a high-density cell array method. Proc. Natl. Acad. Sci. USA 102, 7215-7220. 